International Journal of Pure and Applied Mathematics

Volume 94 No. $1 \quad 2014,21-35$

ISSN: $1311-8080$ (printed version); ISSN: 1314-3395 (on-line version)

url: http://www.ijpam.eu

doi: http://dx.doi.org/10.12732/ijpam.v94i1.3

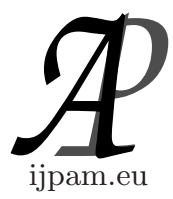

\title{
COMMON FIXED POINT THEOREMS FOR GENERALIZED FUZZY $(\psi, \varphi)$-WEAKLY CONTRACTIVE MAPPINGS
}

\author{
Li Zhu ${ }^{1}$, Pei Hua Zhong ${ }^{2}$ \\ 1,2 Department of Mathematics \\ Jiangxi Agricultural University \\ Nanchang 330045, P.R. CHINA
}

\begin{abstract}
In this paper, we prove some common fuzzy fixed point theorems and common fixed point theorems for a pair of generalized fuzzy $(\psi, \varphi)$-weakly contractive mappings in complete ordered metric spaces. Our results generalize some related results in the literature.
\end{abstract}

AMS Subject Classification: 47H10, 54H 25

Key Words: common fixed point, fuzzy mapping, fuzzy fixed point, weakly contractive

\section{Introduction and Preliminaries}

Banach contraction mapping principle is one of the pivotal results of analysis and has applications in a number of branches of mathematics. Generalization of Banach contraction mapping principle has been a very active field of research during recent years. Weakly contractive mappings have been dealt with in a number of papers (see [6], [7], [16], [17], [19], [21], and references). Also, a generalization of Banach contraction mapping principle was suggested Dutta and Choudhury. The result of Dutta and Choudhury [11] state as follows.

Received: September 5, 2013

(c) 2014 Academic Publications, Ltd. url: www.acadpubl.eu

${ }^{\S}$ Correspondence author 
Theorem 1.1. (see [11]) Let $(X, d)$ be a complete metric space and $T$ : $X \rightarrow X$ be a self-mapping satisfying the inequality

$$
\psi(d(T x, T y)) \leq \psi(d(x, y))-\varphi(d(x, y))
$$

where $\psi, \varphi:[0, \infty) \rightarrow[0, \infty)$ are both continuous and monotone nondecreasing functions with $\psi(t)=\varphi(t)=0$ if and only if $t=0$. Then $T$ has a unique fixed point.

Remark 1.1. A mappings defined in Theorem 1.1 may be called $(\psi, \varphi)$ weak contraction.

Dorić [10] established the following fixed point theorem for two mappings which generalized Theorem 1.1 .

Theorem 1.2. (see [10]) Let $(X, d)$ be a complete metric space and $T, S$ : $X \rightarrow X$ be two self-mappings such that for all $x, y \in X$

$$
\psi(d(T x, S y)) \leq \psi(M(x, y))-\varphi(M(x, y))
$$

where:

(a) $\psi:[0, \infty) \rightarrow[0, \infty)$ is a continuous monotone nondecreasing function with $\psi(t)=0$ if and only if $t=0$.

(b) $\varphi:[0, \infty) \rightarrow[0, \infty)$ is a lower semi-continuous function with $\varphi(t)=0$ if and only if $t=0$.

(c) $M(x, y)=\max \left\{d(x, y), d(T x, x), d(S y, y), \frac{1}{2}[d(y, T x)+d(x, S y)]\right\}$.

Then there exists the unique point $u \in X$ such that $u=T u=S u$.

Remark 1.2. Two self-mappings defined in Theorem 1.2 may be called generalized $(\psi, \varphi)$-weak contractions.

In 1981, Heilpern [13] introduced the concept of fuzzy contraction mappings and established Banach contraction principle for fuzzy mappings in complete metric linear spaces. Since then many scholars studied the existence of fixed points of fuzzy mappings satisfying some contractive-type conditions ( see [1]$[5],[14],[20],[22]$ and references). For the sake of convenience, we first recall some definitions.

Let $(X, d)$ be a metric space, a fuzzy set in $X$ is a function with domain $X$ and values in $I=[0,1]$. If $A$ is a fuzzy set and $x \in X$, then the function value $A(x)$ is called the grade of membership of $x$ in $A$. The collection of all fuzzy sets in $X$ is denoted by $I^{X}$. 
The $\alpha$-level set of $A$, denoted by $[A]_{\alpha}$, is defined as

$$
\begin{aligned}
{[A]_{\alpha} } & =\{x: A(x) \geq \alpha\}, \quad \text { if } \alpha \in(0,1], \\
{[A]_{0} } & =\overline{\{x: A(x)>0\} .}
\end{aligned}
$$

where $\bar{B}$ is the closure of the non-fuzzy set $B$.

Let $\alpha \in[0,1]$, then the family $W_{\alpha}(X)$ is given by $\left\{A \in I^{X}:[A]_{\alpha}\right.$ is non empty convex and compact $\}$. Denote by $W(X)$ the totality of fuzzy sets which satisfy that for each $\alpha \in I,[A]_{\alpha}$ is non-empty convex and compact in $X$ and $\sup A(x)=1$. Let $A, B \in W(X)$, then $A$ is said to be more accurate than $B$, $x \in X$ denoted by $A \subset B$, if and only if $A(x) \leq B(x)$, for each $x \in X$.

For $A, B \in W(X), \alpha \in[0,1]$, define

$$
\begin{aligned}
P_{\alpha}(A, B) & =\inf _{x \in[A]_{\alpha}, y \in[B]_{\alpha}} d(x, y), \\
D_{\alpha}(A, B) & =H\left([A]_{\alpha},[B]_{\alpha}\right), \\
P(A, B) & =\sup _{\alpha} P_{\alpha}(A, B), \\
D(A, B) & =\sup _{\alpha} D_{\alpha}(A, B),
\end{aligned}
$$

where $H$ is the Hausdorff metric induced by the metric $d$.

For $x \in X$, we write $\{x\}$ the characteristic function of the ordinary subset $\{x\}$ of $X$. For $\alpha \in(0,1]$, the fuzzy point $x_{\alpha}$ of $X$ is the fuzzy set of $X$ given by $x_{\alpha}(x)=\alpha$ and $x_{\alpha}(z)=0$ if $z \neq x$ (see [12]).

Let $X$ be an arbitrary set and $Y$ a metric space. A mapping $T$ is called fuzzy mapping if $T$ is a mapping from $X$ into $I^{Y}$, that is, $T x \in I^{Y}$ for each $x$ in $X$. A fuzzy point $x_{\alpha}$ in $X$ is called a fuzzy fixed point of the fuzzy mapping $T$ if $x_{\alpha} \subset T x$. If $\{x\} \subset T x$, then $x$ is a fixed point of $T$.

Definition 1.1. (see [9]) Let $X$ be a nonempty set. Then $(X, d, \leq)$ is called an ordered metric space iff:

(i) $(X, d)$ is a metric space,

(ii) $(X, \leq)$ is partial ordered.

Definition 1.2. (see [9]) Let $(X, \leq)$ be a partial ordered set, $x, y \in X$ are called comparable if $x \leq y$ or $y \leq x$ holds.

Definition 1.3. (see [15]) A function $\psi:[0, \infty) \rightarrow[0, \infty)$ is called an altering distance function if the following properties are satisfied: 
(i) $\psi$ is nondecreasing and continuous,

(ii) $\psi(t)=0$ if and only if $t=0$.

In 2011, Ćirić and Abbas [9] established a common fuzzy fixed point theorem of fuzzy mappings in ordered metric spaces which generalized Theorem 1.2. We state the result of $C^{\prime}$ irić and Abbas [9] in the following.

Theorem 1.3. (see [9]) Let $X$ be a complete ordered space. Suppose that $T_{1}, T_{2}: X \rightarrow W_{\alpha}(X)$ are two fuzzy mapping on $X$ satisfying

$$
\varphi\left(D_{\alpha}\left(T_{1} x, T_{2} y\right)\right) \leq \varphi(d(x, y))-\phi(d(x, y))
$$

for all comparable elements $x, y \in X$, where $\varphi:[0, \infty) \rightarrow(0, \infty)$ is an altering distance function and $\phi:[0, \infty) \rightarrow(0, \infty)$ is lower semi-continuous with $\phi(t)=$ 0 if and only if $t=0$. Suppose that if $\{y\} \subset T_{1}\left(x_{0}\right)$, then $y, x_{0} \in X$ are comparable. Further, if $x, y \in X$ are comparable, then every $u \in\left(T_{1} x\right)_{\alpha}$ and every $v \in\left(T_{2} y\right)_{\alpha}$ are comparable. Also suppose that if a sequence $\left\{x_{n}\right\} \rightarrow x$ and its consecutive terms are comparable, then $x_{n}, x \in X$ are comparable for all $n$. Then there exists a point $x$ in $X$ such that $x_{\alpha} \subset T_{1} x$ and $x_{\alpha} \subset T_{2} x$.

The main purpose of this paper is to establish common fuzzy fixed point theorems and common fixed point theorems for a pair of generalized fuzzy $(\psi, \varphi)$-weakly contractive mappings on complete ordered metric spaces. Our results generalize Theorem 1.3 and extend the results of [4],[8]-[10],[13] and $[20]$.

\section{Common Fixed Point Theorems}

The following lemma is important in proving our main results.

Lemma 2.1. (see [18]) Let $A$ and $B$ be nonempty closed and bounded subsets of a metric space $(X, d)$. If $a \in A$, then $d(a, B) \leq H(A, B)$.

Let $(X, d)$ be a metric space, $T_{1}, T_{2}: X \rightarrow W(X)$. For each $x, y \in X$ and $\alpha, \beta \in(0,1]$, we put

$$
\begin{aligned}
M(x, y, \alpha, \beta)= & \max \left\{d(x, y), d\left(x,\left[T_{1} x\right]_{\alpha}\right), d\left(y,\left[T_{2} y\right]_{\beta}\right),\right. \\
& \left.\frac{1}{2}\left[d\left(x,\left[T_{2} y\right]_{\beta}\right)+d\left(y,\left[T_{1} x\right]_{\alpha}\right)\right]\right\}
\end{aligned}
$$




$$
\begin{gathered}
M(x, y, \alpha)=\max \left\{d(x, y), d\left(x,\left[T_{1} x\right]_{\alpha}\right), d\left(y,\left[T_{2} y\right]_{\alpha}\right),\right. \\
\left.\quad \frac{1}{2}\left[d\left(x,\left[T_{2} y\right]_{\alpha}\right)+d\left(y,\left[T_{1} x\right]_{\alpha}\right)\right]\right\}, \\
m(x, y)=\max \left\{d(x, y), p\left(x, T_{1} x\right), p\left(y, T_{2} y\right), \frac{1}{2}\left[p\left(x, T_{2} y\right)+p\left(y, T_{1} x\right)\right]\right\} .
\end{gathered}
$$

Let $\Psi=\{\varphi:[0, \infty) \rightarrow[0, \infty) \mid \varphi$ is lower semi-continuous with $\varphi(t)=0$ if and only if $t=0\}$.

Theorem 2.1. Let $(X, d, \leq)$ be a complete ordered metric space and $T_{1}, T_{2}: X \rightarrow I^{X}$ two fuzzy mappings. Assume that the following conditions hold:

(i) for every $x \in X$, there exist $\alpha_{T_{1}}(x), \alpha_{T_{2}}(x) \in(0,1]$ such that $\left[T_{1} x\right]_{\alpha_{T_{1}}(x)}$, $\left[T_{2} x\right]_{\alpha_{T_{2}}(x)} \in W(X)$,

(ii) if $y \in\left[T_{i} x_{0}\right]_{\alpha_{T_{i}}\left(x_{0}\right)}, i=1,2$, then $y, x_{0} \in X$ are comparable,

(iii) for a sequence $\left\{x_{n}\right\} \subset X$, if its consecutive terms are comparable, then $x_{n}, x_{m} \in X$ are comparable for all $n, m$. And if $\left\{x_{n}\right\} \rightarrow x$, then $x_{n}, x \in X$ are comparable for all $n$,

$$
\begin{aligned}
& \psi\left(H\left(\left[T_{1} x\right]_{\alpha_{T_{1}}(x)},\left[T_{2} y\right]_{\alpha_{T_{2}}(y)}\right)\right) \\
\leq & \psi\left(M\left(x, y, \alpha_{T_{1}}(x), \alpha_{T_{2}}(y)\right)\right)-\varphi\left(M\left(x, y, \alpha_{T_{1}}(x), \alpha_{T_{2}}(y)\right)\right)
\end{aligned}
$$

for all comparable $x, y \in X$, where $\psi$ is an altering distance function and $\varphi \in \Psi$.

Then there exists a point $x \in X$ such that $x \in\left[T_{1} x\right]_{\alpha_{T_{1}}(x)} \cap\left[T_{2} x\right]_{\alpha_{T_{2}}(x)}$.

Proof. We shall complete the proof by three steps.

Step 1 Choose $x_{0} \in X$, from condition (i), there exists $\alpha_{T_{1}}\left(x_{0}\right) \in(0,1]$ such that $\left[T_{1} x_{0}\right]_{\alpha_{T_{1}}\left(x_{0}\right)} \in W(X)$. For convenience, we denote $\alpha_{T_{1}}\left(x_{0}\right)$ by $\alpha_{1}$. By the compactness of $\left[T_{1}\left(x_{0}\right)\right]_{\alpha_{1}}$, there exists $x_{1} \in\left[T_{1}\left(x_{0}\right)\right]_{\alpha_{1}}$ such that $d\left(x_{0}, x_{1}\right)=$ $d\left(x_{0},\left[T_{1}\left(x_{0}\right)\right]_{\alpha_{1}}\right)$, and from condition (ii), $x_{0}, x_{1}$ are comparable. Again, there exists $\alpha_{T_{2}}\left(x_{1}\right) \in(0,1]$ such that $\left[T_{2} x_{1}\right]_{\alpha_{T_{2}}\left(x_{1}\right)} \in W(X)$, denote $\alpha_{T_{2}}\left(x_{1}\right)$ by $\alpha_{2}$, and by the compactness of $\left[T_{2}\left(x_{1}\right)\right]_{\alpha_{2}}$, there exists $x_{2} \in\left[T_{2}\left(x_{1}\right)\right]_{\alpha_{2}}$ such that $d\left(x_{1}, x_{2}\right)=d\left(x_{1},\left[T_{2}\left(x_{1}\right)\right]_{\alpha_{2}}\right)$. Moreover, $x_{1}, x_{2}$ are comparable. Continuing this process, we can construct a sequence $\left\{x_{n}\right\}$ in $X$ such that

$$
\begin{aligned}
& x_{2 k+1} \in\left[T_{1} x_{2 k}\right]_{\alpha_{2 k+1}}, \\
& x_{2 k+2} \in\left[T_{2} x_{2 k+1}\right]_{\alpha_{2 k+2}}, \quad k=0,1,2, \cdots,
\end{aligned}
$$


and

$$
\begin{aligned}
d\left(x_{2 k}, x_{2 k+1}\right) & =d\left(x_{2 k},\left[T_{1}\left(x_{2 k}\right)\right]_{\alpha_{2 k+1}}\right), \\
d\left(x_{2 k+1}, x_{2 k+2}\right) & =d\left(x_{2 k+1},\left[T_{2}\left(x_{2 k+1}\right)\right]_{\alpha_{2 k+2}}\right), \quad k=0,1,2, \cdots .
\end{aligned}
$$

Then by the conditions (ii) and (iii), $x_{n}, x_{m} \in X$ are comparable for all $n, m$, and thus

$$
\begin{aligned}
& M\left(x_{2 k}, x_{2 k+1}, \alpha_{2 k+1}, \alpha_{2 k+2}\right) \\
= & \max \left\{d\left(x_{2 k}, x_{2 k+1}\right), d\left(x_{2 k},\left[T_{1} x_{2 k}\right]_{\alpha_{2 k+1}}\right), d\left(x_{2 k+1},\left[T_{2} x_{2 k+1}\right]_{\alpha_{2 k+2}}\right),\right. \\
& \left.\frac{1}{2}\left[d\left(x_{2 k},\left[T_{2} x_{2 k+1}\right]_{\alpha_{2 k+2}}\right)+d\left(x_{2 k+1},\left[T_{1} x_{2 k}\right]_{\alpha_{2 k+1}}\right)\right]\right\} \\
= & \max \left\{d\left(x_{2 k}, x_{2 k+1}\right), d\left(x_{2 k+1}, x_{2 k+2}\right)\right\} .
\end{aligned}
$$

Suppose that $0 \leq d\left(x_{2 k}, x_{2 k+1}\right)<d\left(x_{2 k+1}, x_{2 k+2}\right)$, then

$$
M\left(x_{2 k}, x_{2 k+1}, \alpha_{2 k+1}, \alpha_{2 k+2}\right)=d\left(x_{2 k+1}, x_{2 k+2}\right)>0 .
$$

By Lemma 2.1, we have

$$
d\left(x_{2 k+1}, x_{2 k+2}\right) \leq H\left(\left[T_{1} x_{2 k}\right]_{\alpha_{2 k+1}},\left[T_{2} x_{2 k+1}\right]_{\alpha_{2 k+2}}\right), k=0,1,2, \cdots .
$$

Applying (2.1) with $x=x_{2 k}, y=x_{2 k+1}$, and using the monotone property of $\varphi$, we have

$$
\begin{aligned}
\psi\left(d\left(x_{2 k+1}, x_{2 k+2}\right)\right) \leq & \psi\left(H\left(\left[T_{1} x_{2 k}\right]_{\alpha_{2 k+1}},\left[T_{2} x_{2 k+1}\right]_{\alpha_{2 k+2}}\right)\right) \\
\leq & \psi\left(M\left(x_{2 k}, x_{2 k+1}, \alpha_{2 k+1}, \alpha_{2 k+2}\right)\right) \\
& -\varphi\left(M\left(x_{2 k}, x_{2 k+1}, \alpha_{2 k+1}, \alpha_{2 k+2}\right)\right) \\
= & \psi\left(d\left(x_{2 k+1}, x_{2 k+2}\right)\right)-\varphi\left(d\left(x_{2 k+1}, x_{2 k+2}\right)\right) .
\end{aligned}
$$

This implies that $\left.d\left(x_{2 k+1}, x_{2 k+2}\right)\right)=0$, which is a contradiction.

Thus

$$
d\left(x_{2 k+1}, x_{2 k+2}\right) \leq d\left(x_{2 k}, x_{2 k+1}\right) .
$$

Moreover, we have

$$
\begin{gathered}
M\left(x_{2 k}, x_{2 k+1}, \alpha_{2 k+1}, \alpha_{2 k+2}\right)=d\left(x_{2 k}, x_{2 k+1}\right), \\
\psi\left(d\left(x_{2 k+1}, x_{2 k+2}\right)\right) \leq \psi\left(d\left(x_{2 k}, x_{2 k+1}\right)\right)-\varphi\left(d\left(x_{2 k}, x_{2 k+1}\right)\right) .
\end{gathered}
$$

Similarly, we can deduce that

$$
d\left(x_{2 k}, x_{2 k+1}\right) \leq d\left(x_{2 k-1}, x_{2 k}\right),
$$




$$
\begin{gathered}
M\left(x_{2 k}, x_{2 k-1}, \alpha_{2 k+1}, \alpha_{2 k}\right)=d\left(x_{2 k-1}, x_{2 k}\right), \\
\psi\left(d\left(x_{2 k}, x_{2 k+1}\right)\right) \leq \psi\left(d\left(x_{2 k-1}, x_{2 k}\right)\right)-\varphi\left(d\left(x_{2 k-1}, x_{2 k}\right)\right) .
\end{gathered}
$$

Therefore, for all $n \in N$,

$$
\begin{gathered}
0 \leq d\left(x_{n}, x_{n+1}\right) \leq d\left(x_{n-1}, x_{n}\right), \\
\psi\left(d\left(x_{n}, x_{n+1}\right)\right) \leq \psi\left(d\left(x_{n-1}, x_{n}\right)\right)-\varphi\left(d\left(x_{n-1}, x_{n}\right)\right),
\end{gathered}
$$

inequality (2.2) shows that there exists a real number $r \geq 0$ such that

$$
\lim _{n \rightarrow \infty} d\left(x_{n}, x_{n+1}\right)=r .
$$

Suppose that $r>0$, then

$$
0<\psi(r) \leq \psi\left(d\left(x_{n}, x_{n+1}\right)\right) \leq \psi\left(d\left(x_{n-1}, x_{n}\right)\right)-\varphi\left(d\left(x_{n-1}, x_{n}\right)\right) .
$$

Letting $n \rightarrow \infty$ and using the continuity of $\psi$ and lower semi-continuity of $\varphi$, we have

$$
\psi(r) \leq \psi(r)-\varphi(r),
$$

which is a contradiction unless $r=0$. Hence

$$
\lim _{n \rightarrow \infty} d\left(x_{n}, x_{n+1}\right)=0 .
$$

Step 2 We next prove that $\left\{x_{n}\right\}$ is a Cauchy sequence in $X$. In view of (2.4), it suffice to show that the subsequence $\left\{x_{2 n}\right\}$ is a Cauchy sequence. Assume that $\left\{x_{2 n}\right\}$ is not a Cauchy sequence, then there exists some $\varepsilon>0$ for which we can find subsequences $\left\{x_{2 m(k)}\right\}$ and $\left\{x_{2 n(k)}\right\}$ of $\left\{x_{2 n}\right\}$ such that $n(k)$ is the smallest index for which

$$
n(k)>m(k)>k, \quad d\left(x_{2 m(k)}, x_{2 n(k)}\right) \geq \varepsilon .
$$

This means that

$$
d\left(x_{2 m(k)}, x_{2 n(k)-2}\right)<\varepsilon .
$$

Now

$$
\begin{aligned}
& \varepsilon \leq d\left(x_{2 m(k)}, x_{2 n(k)}\right) \\
\leq & d\left(x_{2 m(k)}, x_{2 n(k)-2}\right)+d\left(x_{2 n(k)-2}, x_{2 n(k)-1}\right)+d\left(x_{2 n(k)-1}, x_{2 n(k)}\right) \\
< & \varepsilon+d\left(x_{2 n(k)-2}, x_{2 n(k)-1}\right)+d\left(x_{2 n(k)-1}, x_{2 n(k)}\right) .
\end{aligned}
$$


Letting $k \rightarrow \infty$, by (2.4), we conclude that

$$
\lim _{k \rightarrow \infty} d\left(x_{2 m(k)}, x_{2 n(k)}\right)=\varepsilon .
$$

Again

$$
\begin{gathered}
\left|d\left(x_{2 m(k)-1}, x_{2 n(k)}\right)-d\left(x_{2 m(k)}, x_{2 n(k)}\right)\right| \leq d\left(x_{2 m(k)}, x_{2 m(k)-1}\right), \\
\left|d\left(x_{2 n(k)+1}, x_{2 m(k)}\right)-d\left(x_{2 m(k)}, x_{2 n(k)}\right)\right| \leq d\left(x_{2 n(k)}, x_{2 n(k)+1}\right) .
\end{gathered}
$$

Letting $k \rightarrow \infty$ in (2.7) and (2.8), by (2.4) and (2.6), we obtain

$$
\lim _{k \rightarrow \infty} d\left(x_{2 m(k)-1}, x_{2 n(k)}\right)=\lim _{k \rightarrow \infty} d\left(x_{2 n(k)+1}, x_{2 m(k)}\right)=\varepsilon .
$$

Similarly, we have

$$
\lim _{k \rightarrow \infty} d\left(x_{2 m(k)-1}, x_{2 n(k)+1}\right)=\varepsilon .
$$

Applying (2.1) with $x=x_{2 n(k)}, y=x_{2 m(k)-1}$, we have

$$
\begin{aligned}
& \psi\left(d\left(x_{2 n(k)+1}, x_{2 m(k)}\right)\right) \\
\leq & \psi\left(H\left(\left[T_{1} x_{2 n(k)}\right]_{\alpha_{2 n(k)+1}},\left[T_{2} x_{2 m(k)-1}\right]_{\left.\alpha_{2 m(k)}\right)}\right)\right) \\
\leq & \psi\left(M\left(x_{2 n(k)}, x_{2 m(k)-1}, \alpha_{2 n(k)+1}, \alpha_{2 m(k)}\right)\right) \\
& -\varphi\left(M\left(x_{2 n(k)}, x_{2 m(k)-1}, \alpha_{2 n(k)+1}, \alpha_{2 m(k)}\right)\right) .
\end{aligned}
$$

where

$$
\begin{aligned}
& M\left(x_{2 n(k)}, x_{2 m(k)-1}, \alpha_{2 n(k)+1}, \alpha_{2 m(k)}\right) \\
= & \max \left\{d\left(x_{2 n(k)}, x_{2 m(k)-1}\right), d\left(x_{2 n(k)},\left[T_{1} x_{2 n(k)}\right]_{\alpha_{2 n(k)+1}}\right),\right. \\
& d\left(x_{2 m(k)-1},\left[T_{2} x_{2 m(k)-1}\right]_{\alpha_{2 m(k)}}\right), \\
& \frac{1}{2}\left[d\left(x_{2 n(k)},\left[T_{2} x_{2 m(k)-1}\right]_{\alpha_{2 m(k)}}\right)+d\left(x_{2 m(k)-1},\left[T_{1} x_{2 n(k)}\right]_{\left.\left.\left.\alpha_{2 n(k)+1}\right)\right]\right\} .}\right.\right.
\end{aligned}
$$

Letting $k \rightarrow \infty$ in (2.11) and using the continuity of $\psi$ and lower semicontinuity of $\varphi$, by (2.4), (2.6), (2.9), (2.10) and (2.12), we have

$$
\psi(\varepsilon) \leq \psi(\varepsilon)-\varphi(\varepsilon),
$$

which is a contradiction with $\varepsilon>0$. 
Therefore, $\left\{x_{n}\right\}$ is a Cauchy sequence in $(X, d)$. Since $(X, d)$ is complete, there exists some $x \in X$ such that $x_{n} \rightarrow x$ as $n \rightarrow \infty$, and $x_{n}, x \in X$ are comparable for all $n$.

Step 3 Now we show that $d\left(x,\left[T_{1} x\right]_{\alpha_{T_{1}(x)}}\right)=0$.

From

$$
\begin{aligned}
\left|d\left(x,\left[T_{1} x\right]_{\alpha_{T_{1}(x)}}\right)-d\left(x, x_{2 n}\right)\right| & \leq d\left(x_{2 n},\left[T_{1} x\right]_{\alpha_{T_{1}(x)}}\right) \\
& \leq H\left(\left[T_{2} x_{2 n-1}\right]_{\alpha_{2 n}},\left[T_{1} x\right]_{\alpha_{T_{1}(x)}}\right)
\end{aligned}
$$

and the condition (iv), we have

$$
\begin{aligned}
& \psi\left(\left|d\left(x,\left[T_{1} x\right]_{\alpha_{T_{1}(x)}}\right)-d\left(x, x_{2 n}\right)\right|\right) \\
\leq & \psi\left(H\left(\left[T_{2} x_{2 n-1}\right]_{\alpha_{2 n}},\left[T_{1} x\right]_{\left.\alpha_{T_{1}(x)}\right)}\right)\right) \\
\leq & \psi\left(M\left(x, x_{2 n-1}, \alpha_{T_{1}(x)}, \alpha_{2 n}\right)\right)-\varphi\left(M\left(x, x_{2 n-1}, \alpha_{T_{1}(x)}, \alpha_{2 n}\right)\right)
\end{aligned}
$$

where

$$
\begin{aligned}
& M\left(x, x_{2 n-1}, \alpha_{T_{1}(x)}, \alpha_{2 n}\right) \\
= & \max \left\{d\left(x, x_{2 n-1}\right), d\left(x,\left[T_{1} x\right]_{\alpha_{T_{1}(x)}}\right), d\left(x_{2 n-1},\left[T_{2}\left(x_{2 n-1}\right)\right]_{\alpha_{2 n}}\right),\right. \\
& \left.\frac{1}{2}\left[d\left(x,\left[T_{2}\left(x_{2 n-1}\right)\right]_{\alpha_{2 n}}\right)+d\left(x_{2 n-1},\left[T_{1} x\right]_{\alpha_{T_{1}(x)}}\right)\right]\right\} .
\end{aligned}
$$

Letting $n \rightarrow \infty$ in (2.13), by the continuity of $\psi$ and lower semi-continuity of $\varphi$ and (2.4), we have

$$
\psi\left(d\left(x,\left[T_{1} x\right]_{\alpha_{T_{1}(x)}}\right)\right) \leq \psi\left(d\left(x,\left[T_{1} x\right]_{\alpha_{T_{1}(x)}}\right)\right)-\varphi\left(d\left(x,\left[T_{1} x\right]_{\alpha_{T_{1}(x)}}\right)\right),
$$

which implies that $d\left(x,\left[T_{1} x\right]_{\alpha_{T_{1}(x)}}\right)=0$, that is, $x \in\left[T_{1} x\right]_{\alpha_{T_{1}(x)}}$. Similarly, $x \in\left[T_{2} x\right]_{\alpha_{T_{2}(x)}}$. Thus we have $x \in\left[T_{1} x\right]_{\alpha_{T_{1}(x)}} \bigcap\left[T_{2} x\right]_{\alpha_{T_{2}(x)}}$.

Taking $\alpha_{T_{1}(x)}=\alpha_{T_{2}(x)}=\alpha$ for every $x \in X$ in Theorem 2.1, we obtain the following corollary.

Corollary 2.1. Let $(X, d, \leq)$ be a complete ordered metric space and $T_{1}, T_{2}: X \rightarrow I^{X}$ two fuzzy mappings such that the following conditions are satisfied:

(i) for every $x \in X,\left[T_{1} x\right]_{\alpha},\left[T_{2} x\right]_{\alpha} \in W(X)$, where $\alpha \in(0,1]$,

(ii) if $y \in\left[T_{i} x_{0}\right]_{\alpha}, i=1,2$, then $y, x_{0} \in X$ are comparable, 
(iii) for a sequence $\left\{x_{n}\right\} \subset X$, if its consecutive terms are comparable, then $x_{n}, x_{m} \in X$ are comparable for all $n, m$. And if $\left\{x_{n}\right\} \rightarrow x$, then $x_{n}, x \in X$ are comparable for all $n$,

(iv) $\psi\left(D_{\alpha}\left(T_{1} x, T_{2} y\right)\right) \leq \psi(M(x, y, \alpha))-\varphi(M(x, y, \alpha))$ for all comparable $x, y \in X$, where $\psi$ is an altering distance function and $\varphi \in \Psi$.

Then there exists a point $x \in X$ such that $x \in\left[T_{1} x\right]_{\alpha} \cap\left[T_{2} x\right]_{\alpha}$, that is, $x_{\alpha} \subset T_{1} x, x_{\alpha} \subset T_{2} x$.

Theorem 2.2. Let $(X, d)$ be a complete metric space and $T_{1}, T_{2}: x \rightarrow$ $W(X)$ fuzzy mappings such that

$$
\psi\left(D\left(T_{1} x, T_{2} y\right)\right) \leq \psi(m(x, y))-\varphi(m(x, y))
$$

for all $x, y \in X$, where $\psi$ is an altering distance function, $\varphi \in \Psi$ and $\varphi$ is nonincreasing. Then there exists a point $x \in X$ such that $x \in\left[T_{1} x\right]_{1} \cap\left[T_{2} x\right]_{1}$, that is, $\{x\} \subset T_{1} x,\{x\} \subset T_{2} x$.

Proof. Choose $x \in X$, since for all $x \in X,\left[T_{1} x\right]_{1} \subseteq\left[T_{1} x\right]_{\alpha} \in W(X)$ for each $\alpha \in(0,1]$, we have $d\left(x,\left[T_{1} x\right]_{\alpha}\right) \leq d\left(x,\left[T_{1} x\right]_{1}\right)$ for each $\alpha \in(0,1]$, which implies that

$$
p\left(x, T_{1} x\right) \leq d\left(x,\left[T_{1} x\right]_{1}\right) .
$$

Similarly, for $y \in X$,

$$
\begin{aligned}
& p\left(x, T_{2} y\right) \leq d\left(x,\left[T_{2} y\right]_{1}\right), \\
& p\left(y, T_{2} y\right) \leq d\left(y,\left[T_{2} y\right]_{1}\right), \\
& p\left(y, T_{1} x\right) \leq d\left(y,\left[T_{1} x\right]_{1}\right) .
\end{aligned}
$$

Now, for all $x, y \in X$,

$$
\begin{aligned}
& m(x, y) \\
= & \max \left\{d(x, y), p\left(x, T_{1} x\right), p\left(y, T_{2} y\right), \frac{1}{2}\left[p\left(x, T_{2} y\right)+p\left(y, T_{1} x\right)\right]\right\} \\
\leq & \left.\max \left\{d(x, y), d\left(x,\left[T_{1} x\right]_{1}\right)\right), d\left(y,\left[T_{2} y\right]_{1}\right)\right), \\
& \left.\frac{1}{2}\left[d\left(x,\left[T_{2} y\right]_{1}\right)+d\left(y,\left[T_{1} x\right]_{1}\right)\right]\right\} \\
= & M(x, y, 1) .
\end{aligned}
$$

Moreover,

$$
D_{1}\left(T_{1} x, T_{2} y\right) \leq D\left(T_{1} x, T_{2} y\right)
$$


Hence

$$
\begin{aligned}
\psi\left(D_{1}\left(T_{1} x, T_{2} y\right)\right) & \leq \psi\left(D\left(T_{1} x, T_{2} y\right)\right) \\
& \leq \psi(m(x, y))-\varphi(m(x, y)) \\
& \leq \psi(M(x, y, 1))-\varphi(M(x, y, 1)) .
\end{aligned}
$$

So by Corollary 2.1, there exists $x \in X$, such that $x \in\left[T_{1} x\right]_{1} \cap\left[T_{2} x\right]_{1}$, that is, $\{x\} \subset T_{1} x,\{x\} \subset T_{2} x$.

Similar to the proof of Theorem 2.1, we can prove the following theorem.

Theorem 2.3. Let $(X, d, \leq)$ be a complete ordered metric space and $T_{1}, T_{2}: X \rightarrow I^{X}$ two fuzzy mappings such that the following conditions are satisfied:

(i) for every $x \in X$, there exist $\alpha_{T_{1}}(x), \alpha_{T_{2}}(x) \in(0,1]$ such that $\left[T_{1} x\right]_{\alpha_{T_{1}}(x)}$, $\left[T_{2} x\right]_{\alpha_{T_{2}}(x)} \in W(X)$

(ii) if $y \in\left[T_{i} x_{0}\right]_{\alpha_{T_{i}}\left(x_{0}\right)}, i=1,2$, then $y, x_{0} \in X$ are comparable,

(iii) for a sequence $\left\{x_{n}\right\} \subset X$, if its consecutive terms are comparable, then $x_{n}, x_{m} \in X$ are comparable for all $n, m$. And if $\left\{x_{n}\right\} \rightarrow x$, then $x_{n}, x \in X$ are comparable for all $n$,

(iv) $\psi\left(H\left(\left[T_{1} x\right]_{\alpha_{T_{1}}(x)},\left[T_{2} y\right]_{\alpha_{T_{2}}(y)}\right)\right) \leq k \psi\left(M\left(x, y, \alpha_{T_{1}}(x), \alpha_{T_{2}}(y)\right)\right)$ for all comparable $x, y \in X$, where $0<k<1$ and $\psi$ is an altering distance function.

Then there exists a point $x \in X$ such that $x \in\left[T_{1} x\right]_{\alpha_{T_{1}}(x)} \cap\left[T_{2} x\right]_{\alpha_{T_{2}}(x)}$.

Taking $\alpha_{T_{1}(x)}=\alpha_{T_{2}(x)}=\alpha$ for every $x \in X$ in Theorem 2.3, we obtain the following corollary.

Corollary 2.2. Let $(X, d, \leq)$ be a complete ordered metric space and $T_{1}, T_{2}: X \rightarrow I^{X}$ two fuzzy mappings such that the following conditions are satisfied:

(i) for every $x \in X,\left[T_{1} x\right]_{\alpha},\left[T_{2} x\right]_{\alpha} \in W(X)$, where $\alpha \in(0,1]$,

(ii) if $y \in\left[T_{i} x_{0}\right]_{\alpha}, i=1,2$, then $y, x_{0} \in X$ are comparable,

(iii) for a sequence $\left\{x_{n}\right\} \subset X$, if its consecutive terms are comparable, then $x_{n}, x_{m} \in X$ are comparable for all $n, m$. And if $\left\{x_{n}\right\} \rightarrow x$, then $x_{n}, x \in X$ are comparable for all $n$,

(iv) $\psi\left(D_{\alpha}\left(T_{1} x, T_{2} y\right)\right) \leq k \psi(M(x, y, \alpha))$ for all comparable $x, y \in X$, where $0<k<1$ and $\psi$ is an altering distance function.

Then there exists a point $x \in X$ such that $x \in\left[T_{1} x\right]_{\alpha} \cap\left[T_{2} x\right]_{\alpha}$, that is, $x_{\alpha} \subset T_{1} x, x_{\alpha} \subset T_{2} x$. 
Similar to the proof of Theorem 2.2, we can prove the following theorem.

Theorem 2.4. Let $(X, d)$ be a complete metric space and $T_{1}, T_{2}: X \rightarrow$ $W(X)$ two fuzzy mappings such that $\psi\left(D\left(T_{1} x, T_{2} y\right)\right) \leq k \psi(m(x, y))$ for all $x, y \in X$, where $0<k<1$ and $\psi$ is an altering distance function. Then there exists a point $x \in X$ such that $x \in\left[T_{1} x\right]_{1} \cap\left[T_{2} x\right]_{1}$, that is, $\{x\} \subset T_{1} x$, $\{x\} \subset T_{2} x$.

Setting $\psi$ an identity function in Theorem 2.3, Corollary 2.2 and Theorem 2.4 , we have the following results.

Corollary 2.3. Let $(X, d, \leq)$ be a complete ordered metric space and $T_{1}, T_{2}: X \rightarrow I^{X}$ two fuzzy mappings such that the following conditions are satisfied:

(i) for every $x \in X$, there exist $\alpha_{T_{1}}(x), \alpha_{T_{2}}(x) \in(0,1]$ such that $\left[T_{1} x\right]_{\alpha_{T_{1}}(x)}$, $\left[T_{2} x\right]_{\alpha_{T_{2}}(x)} \in W(X)$

(ii) if $y \in\left[T_{i} x_{0}\right]_{\alpha_{T_{i}}\left(x_{0}\right)}, i=1,2$, then $y, x_{0} \in X$ are comparable,

(iii) for a sequence $\left\{x_{n}\right\} \subset X$, if its consecutive terms are comparable, then $x_{n}, x_{m} \in X$ are comparable for all $n, m$. And if $\left\{x_{n}\right\} \rightarrow x$, then $x_{n}, x \in X$ are comparable for all $n$,

(iv) $H\left(\left[T_{1} x\right]_{\alpha_{T_{1}}(x)},\left[T_{2} y\right]_{\alpha_{T_{2}}(y)}\right) \leq k M\left(x, y, \alpha_{T_{1}}(x), \alpha_{T_{2}}(y)\right)$ for all comparable $x, y \in X$, where $0<k<1$.

Then there exists a point $x \in X$ such that $x \in\left[T_{1} x\right]_{\alpha_{T_{1}}(x)} \cap\left[T_{2} x\right]_{\alpha_{T_{2}}(x)}$.

Corollary 2.4. Let $(X, d, \leq)$ be a complete ordered metric space and $T_{1}, T_{2}: X \rightarrow I^{X}$ two fuzzy mappings such that the following conditions are satisfied:

(i) for every $x \in X,\left[T_{1} x\right]_{\alpha},\left[T_{2} x\right]_{\alpha} \in W(X)$, where $\alpha \in(0,1]$,

(ii) if $y \in\left[T_{i} x_{0}\right]_{\alpha}, i=1,2$, then $y, x_{0} \in X$ are comparable,

(iii) for a sequence $\left\{x_{n}\right\} \subset X$, if its consecutive terms are comparable, then $x_{n}, x_{m} \in X$ are comparable for all $n, m$. And if $\left\{x_{n}\right\} \rightarrow x$, then $x_{n}, x \in X$ are comparable for all $n$,

(iv) $D_{\alpha}\left(T_{1} x, T_{2} y\right) \leq k M(x, y, \alpha)$ for all comparable $x, y \in X$, where $0<$ $k<1$.

Then there exists a point $x \in X$ such that $x \in\left[T_{1} x\right]_{\alpha} \cap\left[T_{2} x\right]_{\alpha}$, that is, $x_{\alpha} \subset T_{1} x, x_{\alpha} \subset T_{2} x$.

Corollary 2.5. (see [21]) Let $(X, d)$ be a complete metric space and $T_{1}, T_{2}$ : $X \rightarrow W(X)$ two fuzzy mappings such that $D\left(T_{1} x, T_{2} y\right) \leq k m(x, y)$ for all 
$x, y \in X$, where $0<k<1$. Then there exists a point $x \in X$ such that $x \in\left[T_{1} x\right]_{1} \cap\left[T_{2} x\right]_{1}$, that is, $\{x\} \subset T_{1} x,\{x\} \subset T_{2} x$.

Letting $T_{1}=T_{2}=T$ in Corollary 2.5, in view of $d(x, y) \leq m(x, y)$ for all $x, y \in X$, we obtain the following corollary.

Corollary 2.6 ([13]) Let $(X, d)$ be a complete metric space and $T: X \rightarrow$ $W(X)$ a fuzzy mapping such that $D(T x, T y) \leq k d(x, y)$ for all $x, y \in X$, where $0<k<1$. Then there exists a point $x \in X$ such that $\{x\} \subset T x$.

\section{References}

[1] M. Abbas, B. Damjanović, R. Lazović, Fuzzy common fixed point theorems for generalized contractive mappings, Appl. Math. Lett., 23 (2010), 13261330. http://dx.doi.org/10.1016/j.aml.2010.06.023

[2] H. M. Abu-Donia, Common fixed point theorems for fuzzy mappings in metric space under $\varphi$-contraction condition, Chaos Solitons Fractals, 34 (2007), 538-543. http://dx.doi.org/10.1016/j.chaos.2005.03.055

[3] A. Azam, M. Arshad, I. Beg, Fixed points of fuzzy contractive and fuzzy locally contractive maps, Chaos Solitons Fractals, 42 (2009), 2836-2841. http://dx.doi.org/10.1016/j.chaos.2009.04.026

[4] A. Azam, M. Arshad, P. Vetro, On a pair of fuzzy $\varphi-$ contractive mappings, Math. Comput. Model., 52 (2010), 207-214. http://dx.doi.org/10.1016/j.mcm.2010.02.010

[5] A. Azam, I. Beg, Common fixed points of fuzzy maps, Math. Comput. Model., 49 (2009), 1331-1336. http://dx.doi.org/10.1016/j.mcm.2008.11.011

[6] I. Beg, M. Abbas, Coincidence point and invariant approximation for mappings satisfying generalized weak contractive condition, Fixed Point Theory Appl., (2006) 1-7. Article ID 74503. http://dx.doi.org/10.1155/FPTA/2006/74503

[7] M. Berzig, E. Karapinar, Fixed point results for $(\alpha \psi, \beta \varphi)$-contractive mappings for a generalized altering distance, Fixed Point Theory Appl., 2013, 2013:205. http://dx.doi.org/10.1186/1687-1812-2013-205

[8] B. S. Choudhury, N. Metiya, Multivalued and singlevalued fixed point results in partially ordered metric spaces, Arab. J. Math. Sci., 17 (2011), 135-151. http://dx.doi.org/10.1016/j.ajmsc.2011.03.001 
[9] L. Ćirić, M. Abbas and B. Damjanović, Common fuzzy fixed point theorems in ordered metric spaces, Math. Comput. Model., 53 (2011), 17371741. http://dx.doi.org/10.1016/j.mcm.2010.12.050

[10] D. Dorić, Common fixed point for generalized $(\varphi, \phi)$-weak contractions, Appl. Math. Lett., 22 (2009), 1896-1900. http://dx.doi.org/10.1016/j.aml.2009.08.001

[11] P. N. Dutta, B. S. Choudhury, A generalization of contraction principle in metric spaces, Fixed Point Theory Appl., (2008) 1-8. Article ID 406368. Doi:10.1155/2008/406368

[12] V. D. Estruch, A. Vidal, A note on fixed fuzzy points for fuzzy mappings, Rend. Istit. Mat. Univ. Trieste, 32 (2001), 39-45. http://hdl.handle.net/10077/4285

[13] S. Heilpern, Fuzzy mappings and fuzzy fixed point theorems, $J$. Math. Anal. Appl., 83 (1981), 566-569. http://dx.doi.org/10.1016/0022247X(81)90141-4

[14] T. Kamran, Common fixed points theorems for fuzzy mappings, Chaos Solitons Fractals, 38 (2008), 1378-1382. http://dx.doi.org/10.1016/j.chaos.2008.04.031

[15] M. S. Khan, M. Swaleh, S. Sessa, Fixed point theorems by altering distances between the points, Bull. Aust. Math. Soc., 30 (1984), 1-9. http://dx.doi.org/10.1017/S0004972700001659

[16] J. H. Mai, X. H. Liu, Fixed points of weakly contractive maps and boundedness of orbits, Fixed Point Theory Appl., (2007) 1-12, Article ID 20962. doi: $10.1155 / 2007 / 20962$

[17] Z. Mustafa, J. R. Roshan, V. Parvaneh, Coupled coincidence point results for $(\psi, \varphi)$-weakly contractive mappings in partially ordered $G_{b}$-metric spaces, Fixed Point Theory Appl., 2013, 2013:206. http://dx.doi.org/10.1186/1687-1812-2013-206

[18] S. B. Nadler, Multivalued contraction mappings, Pacific J. Math., 30 (1969), 475-488. http://projecteuclid.org/euclid.pjm/1102978504

[19] H. K. Nashine, Cyclic generalized $\psi$-weakly contractive mappings and fixed point results with applications to integral equations, Nonlinear Anal., 75 (2012), 6160-6169. http://dx.doi.org/10.1016/j.na.2012.06.021 
[20] J. Y. Park, J. U. Jeong, Fixed point theorems for fuzzy mappings, Fuzzy Sets and Syst., 87 (1997), 111-116. http://dx.doi.org/10.1016/S01650114(96)00013-9

[21] B. E. Rhoades, Some theorems on weakly contractive maps, Nonlinear Anal., 47 (2001), 2683-2693. http://dx.doi.org/10.1016/S0362546X(01)00388-1

[22] L. Zhu, C. X. Zhu, C. F. Chen, Common fixed point theorems for fuzzy mappings in G-metric spaces, Fixed Point Theory Appl., 2012, 2012:159. http://dx.doi.org/10.1186/1687-1812-2012-159 
